\title{
A pilot randomized controlled trial to compare the effectiveness of two 14-day primaquine regimens for the radical cure of vivax malaria in South India
}

\author{
Kavitha Saravu ${ }^{1,2^{*}} \mathbb{0}$, Chaitanya Tellapragada ${ }^{3}$, Shrivathsa Kulavalli ${ }^{2}$, Wilbin Xavier ${ }^{1}$, Shashikiran Umakanth ${ }^{7}$, \\ Gouthami Brahmarouphu ${ }^{4}$, Navyasree Kola Srinivas ${ }^{4}$, Jagadish Puralae Channabasavaiahn, Anzil Bava ${ }^{5}$, \\ Abdul Vahab Saadi ${ }^{5}$, Vasudev Guddattu ${ }^{6}$, Kapaettu Satyamoorthy ${ }^{5}$ and Krishnamurthy Bhat ${ }^{4}$
}

\begin{abstract}
Background: Radical cure of Plasmodium vivax malaria requires treatment with a blood schizonticide and a hypnozoitocide (primaquine) to eradicate the dormant liver stages. There has been uncertainty about the operational effectiveness and optimum dosing of the currently recommended 14-day primaquine $(\mathrm{PQ})$ course.

Methods: A two centre, randomized, open-label, two arm study was conducted in South India. Patients were randomized to receive either high dose ( $0.5 \mathrm{mg}$ base $/ \mathrm{kg}$ body weight) or conventional dose $(0.25 \mathrm{mg} / \mathrm{kg}) \mathrm{PQ}$ for 14 days. Plasma concentrations of $\mathrm{PQ}$ and carboxyprimaquine (CPQ) on the 7th day of treatment were measured by reverse phase high performance liquid chromatography. Study subjects were followed up for 6 months. Recurrent infections were genotyped using capillary fragment length polymorphism of two PCR-amplified microsatellite markers (MS07 and MS 10).
\end{abstract}

Results: Fifty patients were enrolled. Baseline characteristics and laboratory features did not differ significantly between the groups. Mean age of the study population was $42 \pm 16.0$ years. Recurrences $80-105$ days later occurred in 4 (8\%) patients, two in each the groups. All recurrences had the same microsatellite genotype as that causing the index infection suggesting all were relapses. One relapse was associated with low CPQ concentrations suggesting poor adherence.

Conclusions: This small pilot trial supports the effectiveness of the currently recommended lower dose $(0.25 \mathrm{mg} / \mathrm{kg} /$ day) 14 day PQ regimen for the radical cure of vivax malaria in South India.

Trial registration Clinical Trials Registry-India, CTRI/2017/03/007999. Registered 3 March 2017, http://ctri.nic.in/Clinicaltr ials/regtrial.php? modid $=1 \&$ compid $=19 \&$ EncHid $=82755.86366$.

Keywords: Plasmodium vivax, Recurrent malaria, Primaquine, Carboxyprimaquine, Relapse, RP-HPLC, India

\footnotetext{
*Correspondence: kavithasaravu@gmail.com

1 Department of Medicine, Kasturba Medical College, Manipal Academy

of Higher Education, Manipal, Madhava Nagar, Manipal, Karnataka

576104, India

Full list of author information is available at the end of the article
} 


\section{Background}

An estimated 2.5 billion people live in areas where Plasmodium vivax infection is endemic [1]. India, Ethiopia, Indonesia and Pakistan account for $>80 \%$ of the world's vivax malaria [2]. Malaria remains a major public health concern in India where epidemiology varies substantially across the country [3]. Over the past decade, deployment of rapid diagnostic tests, allowing early diagnosis and treatment, and aggressive vector control measures have both helped to reduce malaria case fatality rates significantly. As mortality from falciparum malaria has declined the incidence of $P$. vivax in some states of India has increased. Approximately $12 \%$ of these cases occur in the urban areas [3]. Plasmodium vivax presents a substantial challenge for malaria control and elimination targets because of relapse, resulting from activation of dormant liver stages (hypnozoites) [4]. Prevention of relapse requires use of 8 -aminoquinoline anti-malarials, in addition to schizontocidal treatment of the blood stage infection, with attendant risks of haemolysis in patients who have glucose-6-phosphate dehydrogenase (G6PD) deficiency [5]. Although PQ radical cure is widely recommended it is often not prescribed because G6PD testing is seldom available.

Several different factors determine the radical curative efficacy of PQ. These include the dosage administered, duration of treatment, host genetic polymorphisms in cytochrome P450 metabolizing enzymes (notably 2D6), and parasite susceptibility [6]. Adherence to the currently recommended 14-day PQ regimens is often regarded as poor, although the evidence is conflicting $[6,7]$. The Indian National Vector Borne Disease Programme (NVBDP) recommends radical cure regimen comprising $0.25 \mathrm{mg} / \mathrm{kg}$ body weight for 14 days (http://nvbdcp.gov. in/Doc/National-Drug-Policy-2013.pdf) [8]. In contrast, the Centers for Disease Control and Prevention (CDC), Atlanta, recommends a higher dose regimen $(0.50 \mathrm{mg} /$ $\mathrm{kg}$ body weight for 14 days) [9]. WHO recommends the higher dose PQ regimen for areas with frequent relapse P. vivax strains such as East Asia [12]. There is, therefore, some uncertainty over the optimum dose and the effectiveness of currently recommended regimens. This prospective study compared and evaluated the effectiveness of two radical cure regimens in the treatment of vivax malaria in the South of India.

\section{Methods}

\section{Study population}

Patients with acute vivax malaria attending adult medical units at Kasturba Hospital, Manipal and Dr T M A Pai Hospital, Udupi, India were included in the study, if they met the following inclusion criteria: adults of either gender ( $\geq 18$ years old) with $P$. vivax mono-infection confirmed by microscopy, fever defined as $>37.5^{\circ} \mathrm{C}$ tympanic or oral temperature or a history of fever within previous 3 days, and willing to give informed consent. Pregnant and/or lactating women, and patients with G6PD deficiency or mixed infection with $P$. vivax and Plasmodium falciparum were excluded.

\section{Study design}

This prospective, two-centre, randomized, open-label, two-arm pilot study, enrolled patients from March to August 2017. In this pilot study, it was planned to enroll at least 25 patients in each arm.

\section{Study setting}

Patients were diagnosed with vivax malaria at Kasturba Hospital, Manipal and Dr. Pai Hospital, Udupi, tertiary and secondary care hospitals, respectively, in Udupi district of Karnataka State, India. Udupi district is located $13^{\circ} 32^{\prime} 24.43^{\prime \prime} \mathrm{N}$ latitude and $74^{\circ} 52^{\prime} 26.78^{\prime \prime}$ E longitude, with typical tropical climatic conditions. The monsoon period falls June to October, with average rainfall of more than $4000 \mathrm{~mm}$ every year. Malaria incidence occurs throughout the year in Udupi district with peaks around June to July [10]. The mean annual parasite incidence was estimated as 2.5 per 1000 risk population during years 2012 to 2014 [11]. The catchment area of Kasturba Hospital, Manipal encompasses both the rural and urban population of coastal and interior Karnataka, Goa and Kerala. Kasturba Hospital, Manipal and Dr Pai Hospital, Udupi, record malaria incidence across the year with over 200 malaria cases per annum, each comprising $>55 \% P$. vivax cases.

\section{Subject recruitment and data collection}

Eligible subjects were recruited in the study after obtaining written informed consent. A structured proforma was used to collect data. Data regarding history of fever, headache, vomiting, and past history of malaria, as well as patient's nutritional status, socio-demographic information and general information on diabetes, hypertension, chronic kidney disease, and HIV were collected. Laboratory investigations included haemoglobin, haematocrit, platelet count, erythrocyte sedimentation rate, G6PD levels, urea, creatinine) and schizonticidal treatment [whether chloroquine (CQ) or artemisinin-based combination therapy (ACT)], hypnozoitocidal drug- PQ regimen along with its initiation date. Cases were classified into severe and non-severe cases as per WHO severity criteria [12]. The subjects' follow-up details were also documented, and all the collected data were doubleentered using an electronic clinical record form (SPSS 15). 


\section{Subject allocation and intervention}

After completion of treatment of acute malaria with a schizonticidal drug [either chloroquine $25 \mathrm{mg}$ base $/ \mathrm{kg}$ or ACT (astesunate with doxycycline OR artemetherlumefantrine) as per the treating clinician's judgement of severity], patients were randomized into the study. A block randomization was used to allocate subjects to the groups. Five blocks of size 10 were used. The randomization sequence within each block was done using a lottery method. Eligible patients were allocated to one of the following two treatment groups.

1. Primaquine $0.5 \mathrm{mg}$ base $/ \mathrm{kg} /$ day for 14 days (IPCA Laboratory Pvt Ltd, Mumbai).

2. Primaquine $0.25 \mathrm{mg}$ base $/ \mathrm{kg} /$ day for 14 days (IPCA Laboratory Pvt Ltd, Mumbai).

The subjects were advised to take the drug once a day in the morning after breakfast. Drug dosing was not observed. They were counselled about the importance of PQ for the effective cure of malaria and adherence to medication. Additionally, patients were counselled about personal protective measures against mosquito bite.

\section{Subject follow-up}

The study subjects were followed up on day 7 of PQ treatment for PQ and CPQ estimation. Patients were asked to come for blood draw, $2 \mathrm{~h}$ after the intake of $\mathrm{PQ}$, in a fed state. Self-reported time after intake of PQ to blood collection was noted. Three $\mathrm{ml}$ of venous plasma was collected in EDTA vacutainer for drug estimation. Participants were questioned about compliance to study medication, and confirmed by used blister packs of $\mathrm{PQ}$.

Any adverse events reported by the subject were noted. Patients were encouraged to return if ill. During the follow-up period, peripheral blood smears for parasitic forms were examined on day 28 from onset of illness, followed by a periodic examination by the end of every second month until the completion of 6 months, and if any fever episodes occurred in the follow-up period, the subjects' blood smears were examined for parasitic forms. Treatment adherence, mosquito repellent and bed net usage, intercurrent febrile illnesses and any other possible symptoms of malaria were recorded and documented. In cases with microscopy confirmed recurrence of malaria, patients were treated with $\mathrm{CQ} / \mathrm{ACT}$ as per the severity of illness followed by PQ $0.5 \mathrm{mg} / \mathrm{kg} /$ day for 14 days.

\section{Genetic characterization of Plasmodium vivax for differentiating relapse from re-infection}

During the initial recruitment, $2 \mathrm{ml}$ of blood sample was collected from all study subjects in heparinized vacutainers and preserved in frozen conditions until further testing. Two $\mathrm{ml}$ of heparinized blood was also collected from patients diagnosed (smear positive) with recurrence of malaria. DNA was extracted from the heparinized blood specimens of patients $(n=4)$ collected during initial and recurrent infections of malaria. For DNA extraction, HiPurA ${ }^{\mathrm{TM}}$ Blood Genomic DNA Mini Purification kit meant for DNA isolation from fresh or frozen blood (HiMedia Laboratories, India) was used as per the manufacturer's instructions.

Genotyping of $P$. vivax was performed based on sequence repeats in the microsatellites markers MS7 and MS10 using primers and the method described by Karunaweera et al. [13]. The microsatellite markers were amplified by PCR using $3 \mu \mathrm{l}$ of extracted DNA with a PCR reaction performed in a final volume of $20 \mu \mathrm{l}$ containing $1 \times$ PCR buffer, $2 \mathrm{mM}$ of $\mathrm{MgCl}_{2}$, $200 \mathrm{mM}$ of each dNTP, $0.25 \mathrm{mM}$ of each primer, and 1.5 units of Taq DNA polymerase (Invitrogen). The following thermal cycling conditions were maintained: 5 min at $95{ }^{\circ} \mathrm{C}$ followed by 30 cycles of denaturation for $45 \mathrm{~s}$ at $95{ }^{\circ} \mathrm{C}$, annealing for $45 \mathrm{~s}$ at $56{ }^{\circ} \mathrm{C}$ and $62{ }^{\circ} \mathrm{C}$ (for MS7 and MS10 markers, respectively), and elongation for $1 \mathrm{~min}$ at $72{ }^{\circ} \mathrm{C}$ with a final elongation for $5 \mathrm{~min}$ at $72{ }^{\circ} \mathrm{C}$. Primers for markers MS7 were (6-FAM) $5^{\prime}$-GTA TTCCCCGTCTTGTCC-3' forward and 5'-CTTTCT CCGTTCTTATTTCT-3' reverse; and for MS10 were (NED) 5'-AAGTGTATTTTCCCGACG-3' forward and 5'-CTTTTGCTTGCTCCGTTT-3' reverse, respectively selected from a set of highly polymorphic markers with high heterozygosity in the Sri Lankan endemic populations with vivax malaria [13]. The core repeat sequences of the MS7 marker was (GAA) 9 and that of the MS10 marker was GAA(GGA) ${ }_{2}$ AGA(GGA) ${ }_{9} \mathrm{AGA}(\mathrm{GGA})_{4} \mathrm{AGA}$ GGA A GA (G GA) ${ }_{3}$ A GA G GA A GA (GGA A A A )$_{4}(\mathrm{GGA})_{2}(\mathrm{AGA})_{11}(\mathrm{GGA})_{3}(\mathrm{AGA})_{2}$ GGAAGA $(\mathrm{GGA})_{2}$ with size ranges of amplicons 133-160 for the former and 180-306 for the latter.

PCR was performed with a Genosys PCR thermocycler (MJ Research Model PTC-200, Genosys, Provo, UT, USA). Amplification was confirmed in a $2 \%$ agarose gel and PCR products were stored at $4{ }^{\circ} \mathrm{C}$ in the dark. The product size was resolved by capillary electrophoresis in an ABI Prism 3130 Genetic Analyzer (Applied Biosystems), using GS500 LIZ as the internal size standard and analysed by GeneMapper software (Applied Biosystems). The electropherograms were scored for peaks above a cut-off of 300 relative fluorescent units for true amplification products. Alleles were characterized by the repeat length.

\section{Estimation of $P Q$ and $C P Q$ concentrations}

HPLC method Quantification of the plasma PQ and CPQ levels among all the study subjects during steady 
state (on 7th day after the initiation of PQ) was performed using high-performance liquid chromatography (HPLC). Median plasma PQ and CPQ levels at day 7 were compared among patients of both the groups.

\section{Optimized chromatographic conditions}

In the present study, a reversed phase HPLC (RP-HPLC) method was developed for the estimation of PQ and CPQ using quinine sulfate (QS) as an internal standard (ISTD) with wide linearity range of $150 \mathrm{ng} / \mathrm{ml}$ to $16 \mu \mathrm{g} / \mathrm{ml}$. Separation of $\mathrm{PQ}, \mathrm{CPQ}$ and $\mathrm{QS}$ was achieved on Waters ${ }^{\circledR}$ separation module 2695 by applying isocratic reverse phase mode on Gracesmart RP $C_{18}$ column $(250 \mathrm{~mm} \times 4.6 \mathrm{~mm}$, $5 \mu$ ), using acetonitrile and $10 \mathrm{mM}$ ammonium formate (0.2\% triethyl amine) buffer $\mathrm{pH}$ adjusted to 3.0 with formic acid (30:70,\% v/v) as mobile phase, at a flow rate of $1.0 \mathrm{ml} / \mathrm{min}$, and drug molecules were detected at $265 \mathrm{~nm}$ on Waters ${ }^{\circledR}$ dual absorbance detector 2487 . The column temperature was maintained at $38^{\circ} \mathrm{C}$ and auto sampler at $4{ }^{\circ} \mathrm{C}$, retention time of QS, PQ and CPQ were observed at 4.58, 6.24 and $13.39 \mathrm{~min}$, respectively. The run time was 15 min. Representative chromatogram is shown in Fig. 1.

\section{Optimized liquid-liquid extraction technique}

To $180 \mu \mathrm{l}$ of human plasma, $20 \mu \mathrm{l}$ of $10 \mu \mathrm{g} / \mathrm{ml}$ QS solution and $20 \mu \mathrm{l}$ of working stock of PQ and CPQ were added and vortexed for $2 \mathrm{~min}$. One-thousand micro litre of tertbutyl-methyl-ether and dichloromethane $(2: 1, \% \mathrm{v} / \mathrm{v})$ were added and vortexed for $10 \mathrm{~min}$ for extraction of drug molecules to organic phase. Samples were centrifuged at $10,000 \mathrm{RPM}$ for $15 \mathrm{~min}$ at $4{ }^{\circ} \mathrm{C}$ using cooling centrifuge to separate proteins from the organic phase. The resulted supernatant was collected and evaporated to dryness using nitrogen for $10 \mathrm{~min}$ at $40{ }^{\circ} \mathrm{C}$ under $10 \mathrm{kpa}$ pressure. Finally, the dried residue was reconstituted in $100 \mu \mathrm{l}$ of methanol, and vortexed for $1 \mathrm{~min}$. This solution was transferred to total recovery vial and $40 \mu \mathrm{l}$ of solution was injected into HPLC for analysis [14].

\section{Ethics statement}

The ethics committee of Manipal Academy of Higher Education, (MUEC/021/2016-17) Manipal, India approved the study protocol. A signed written informed consent was obtained from each subject prior to enrolment. If the study subject was illiterate, an impartial third party witnessed the informed consent process. All subjects were informed the nature of the trial and that they were free to withdraw consent to participate at any time. The investigators and study personnel ensured confidentiality of all records.

\section{Data analysis}

Frequency and percentage was used for categorical variable, mean and standard deviation or median and interquartile range was used to analyse continuous variable. Chi square test used to test association between two categorical variables. Independent sample $t$ test was used to compare means across two groups; MannWhitney test was used to compare median across two groups. Data analysis was carried-out by SPSS version 15.

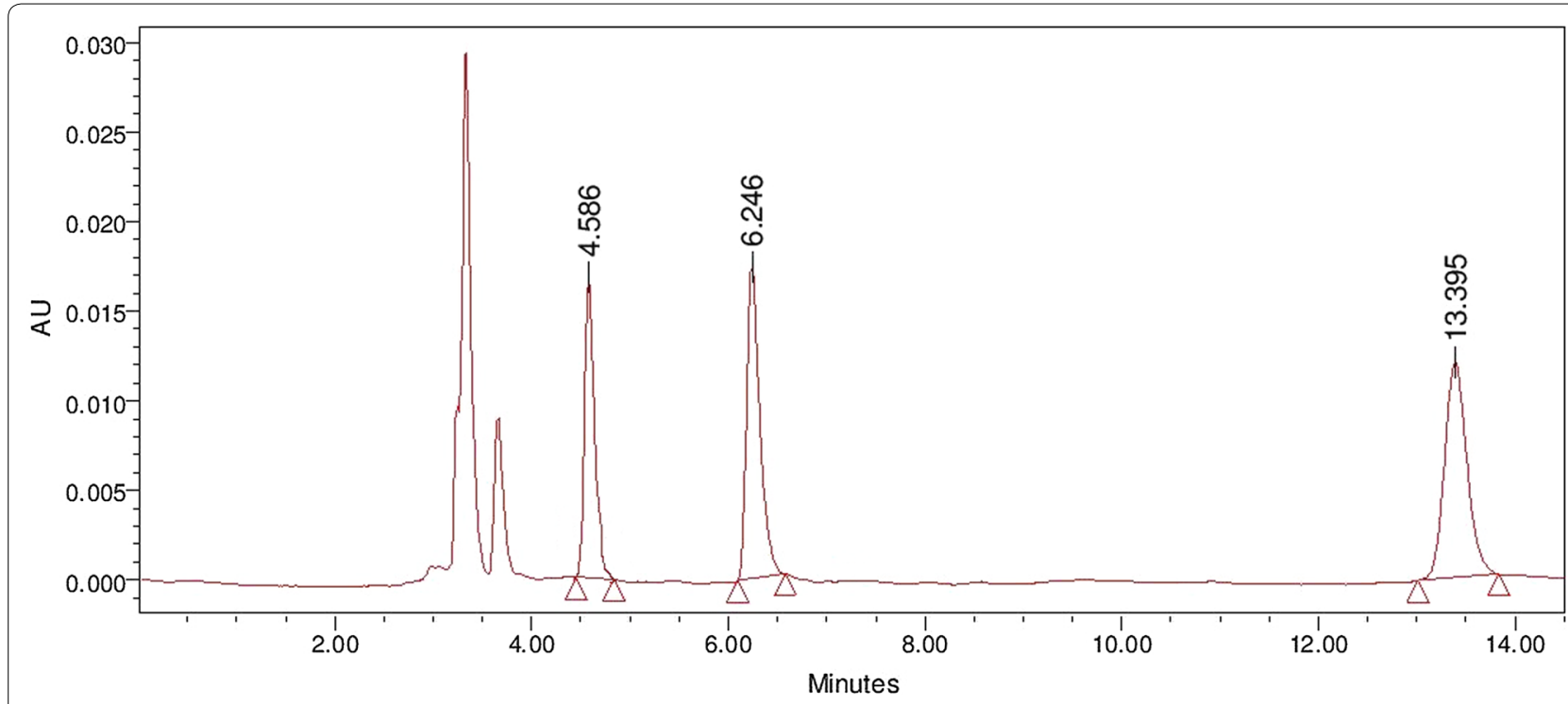

Fig. 1 Chromatogram for quinine sulfate, primaquine and carboxyprimaquine 


\section{Results}

During the recruitment period, 119 individuals were diagnosed with $P$. vivax by microscopy at the two study hospitals (Fig. 2). The main reason for not including patients was if they were unwilling to complete the lengthy follow up $(57,47.9 \%)$. Fifty participants were enrolled and randomized (1:1) to one of the two study arms, of whom $30(60 \%)$ were available for the day 7 follow up for PQ and CPQ estimation A total of 38 participants completed 6 months' follow-up. Only one protocol deviation occurred in which the participant reported $5 \mathrm{~h}$ late for the day 7 follow up drug concentration estimation. The study cohort included $45(90 \%)$ male and $5(10 \%)$ female participants. The mean $( \pm S D)$ age of cohort was $42.0( \pm 16.0)$ years, which ranged from 18 to 76 years. The baseline characteristics and laboratory features of the patients were similar among the treatment groups (Tables 1, 2). Half of the low dose PQ regimen subjects had a chronic disease, although this was not statistically significant.

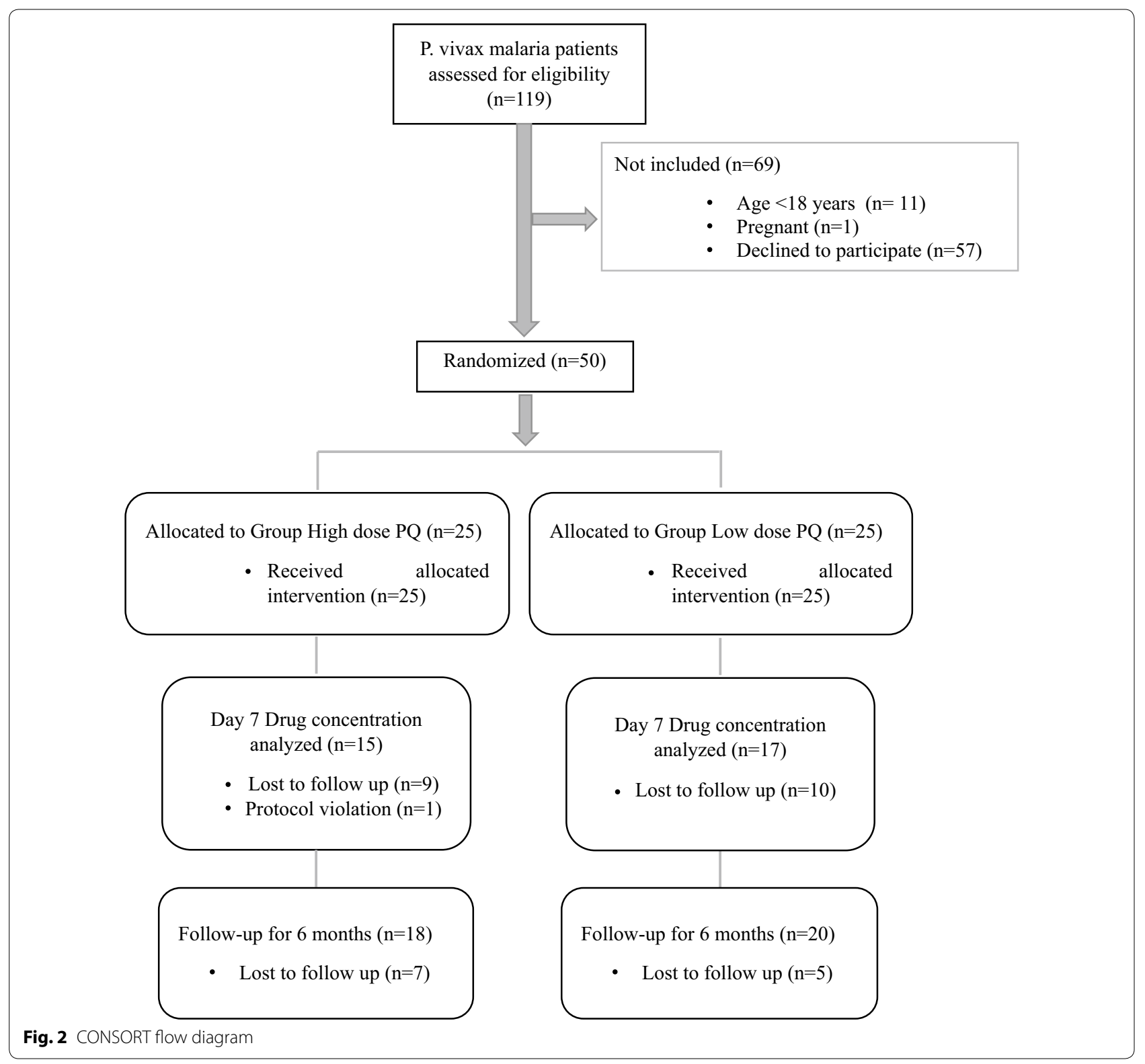


Table 1 Demographic characteristics and outcomes of two groups

\begin{tabular}{|c|c|c|c|}
\hline Characteristic & $\begin{array}{l}\mathrm{PQ} \text { high dose }(\mathrm{N}=25) \mathrm{n}(\%) \\
\text { or Mean } \pm \mathrm{SD}\end{array}$ & $\begin{array}{l}\text { PQ low dose }(N=25) n(\%) \\
\text { or Mean } \pm S D\end{array}$ & $p$-value \\
\hline \multicolumn{4}{|l|}{ Gender } \\
\hline Male & $23(92)$ & $22(88)$ & \multirow[t]{2}{*}{0.63} \\
\hline Female & $2(8)$ & $3(12)$ & \\
\hline Age, years & $42.0 \pm 16.0$ & $40.0 \pm 15.0$ & 0.34 \\
\hline Body weight, kg & $67.9 \pm 14.1$ & $64.6 \pm 13.7$ & 0.40 \\
\hline Body mass index, $\mathrm{kg} / \mathrm{m}^{2}$ & $25.0 \pm 4.0$ & $24.6 \pm 5.2$ & 0.43 \\
\hline Past h/o malaria & $6(24)$ & $11(44)$ & 0.13 \\
\hline \multicolumn{4}{|l|}{ Pre-morbidities } \\
\hline Diabetes mellitus & $2(8)$ & $4(16)$ & 0.38 \\
\hline Hypertension & $2(8)$ & $5(20)$ & 0.22 \\
\hline Chronic kidney disease & 0 & $1(4)$ & 0.31 \\
\hline Heart disease & 0 & $2(8)$ & 0.15 \\
\hline \multicolumn{4}{|l|}{ Severity } \\
\hline Non-severe & $24(96)$ & $24(96)$ & \multirow[t]{2}{*}{1.00} \\
\hline Severe & $1(4)$ & $1(4)$ & \\
\hline \multicolumn{4}{|l|}{ Schizonticidal treatment } \\
\hline Chloroquine & $20(80)$ & $19(76)$ & \multirow[t]{2}{*}{0.73} \\
\hline Artemisinin combination therapy & $5(20)$ & $6(24)$ & \\
\hline \multicolumn{4}{|c|}{ Use of personal protective measures during follow-up } \\
\hline Mosquito repellents & $16(64)$ & $18(72)$ & 0.54 \\
\hline Regular bed net & $3(12)$ & $2(8)$ & 0.63 \\
\hline \multicolumn{4}{|l|}{ Study outcome } \\
\hline Recurrence & $2(4)$ & $2(4)$ & - \\
\hline
\end{tabular}

Table 2 Clinical and laboratory features of two groups

\begin{tabular}{|c|c|c|c|}
\hline & $\begin{array}{l}\mathrm{PQ} \text { high dose }(\mathrm{N}=25) \mathrm{n}(\%) \\
\text { or Mean } \pm \mathrm{SD} \text { or Median (IQR) }\end{array}$ & $\begin{array}{l}\mathrm{PQ} \text { low dose }(\mathrm{N}=25) \mathrm{n}(\%) \\
\text { or Mean } \pm \mathrm{SD} \text { or Median (IQR) }\end{array}$ & $p$-value \\
\hline Fever & $25(100)$ & $25(100)$ & \\
\hline Splenomegaly & $3(12)$ & $2(8)$ & 0.63 \\
\hline Hepatomegaly & $2(8)$ & $2(8)$ & 1.00 \\
\hline Haemoglobin, gm/dl & $13.2 \pm 1.7$ & $13.5 \pm 1.7$ & 0.45 \\
\hline Urea, mg/dl & $33.3 \pm 19.9$ & $31.7 \pm 13.4$ & 0.43 \\
\hline Creatinine, mg/dl & $1.2 \pm 0.4$ & $1.1 \pm 0.4$ & 0.36 \\
\hline Total bilirubin, mg/dl & $1.4(1.3,1.9)$ & $1.5(0.95,3.0)$ & 0.36 \\
\hline Direct bilirubin, mg/dl & $0.6(0.3,0.8)$ & $0.6(0.3,1.4)$ & 0.12 \\
\hline Aspartate amino transferase, IU/I & $39.5(35.5,54.0)$ & $30.0(27.0,41.0)$ & 0.38 \\
\hline Alanine amino transferase, IU/I & $40.5(29.0,67.0)$ & $34.0(24.0,44.0)$ & 0.67 \\
\hline Alkaline phosphatase, IU/I & $87.0(62.5,118.5)$ & $82.0(57.0,110.0)$ & 0.34 \\
\hline$P Q$ concentration $(\mu \mathrm{g} / \mathrm{ml})(\mathrm{N}=30)$ & $0.576(0.186,0.782)$ & $0.184(0.131,0.282)$ & 0.193 \\
\hline Carboxy PQ concentration $(\mu \mathrm{g} / \mathrm{ml})(\mathrm{N}=30)$ & $2.401(1.535,4.119)$ & $2.809(0.817,6.658)$ & 0.945 \\
\hline
\end{tabular}

One patient in each treatment arm had severe malaria. Both regimens were well tolerated. Adherence to the prescribed regimen was complete in $30(60 \%)$ who were available for the day 7 follow up. No significant drug related adverse effects were noted among either study cohort.

In the current study, a sensitive, precise, accurate, reproducible and economic RP-HPLC was developed. QS 
was selected as the internal standard owing to its structural similarity and comparable pKa with PQ and CPQ. This optimized chromatographic method was validated as per US FDA bioanalytical method validation guidelines. Overall precision and accuracy were found to be well within the acceptance range (i.e., $85-115 \%$ ) and lower limit of quantification was found to be $150 \mathrm{ng} /$ $\mathrm{ml}$. Extraction efficiency of the optimized method was found to be $75-91 \%$. Stability of PQ and CPQ in plasma was performed by conducting long-term stability studies for 30 days, where degradation was found to be less than $2.0 \%$. The optimized method was also validated for carryover effect, system suitability, specificity, and sensitivity.

The plasma concentrations of PQ and CPQ has been depicted in Fig. 3. Median concentrations of PQ and CPQ on day 7 were not significantly different amongst the two groups (Table 2). The patient who was sampled after $5 \mathrm{~h}$ for the 7 th day blood sample was excluded from the analysis.

\section{Recurrence}

Recurrent infections occurred in 4 [8\%] patients included in the present study, 2 patients in each arm. (Tables 1,3 ). All presented with uncomplicated malaria. The intervals from starting the initial treatment to recurrence ranged from 80 to 105 days. Survival analysis with time to recurrence among the two regimens has been depicted in Fig. 4.

\section{Genotyping of Plasmodium vivax to differentiate relapse from re-infection}

Genotyping suggested all four recurrences were homologous (isogenic) relapses. All four primary infections were of a single genotype and were different on microsatellite typing, but all four recurrences had the same alleles as the primary infections. Results of the capillary fragment length analysis of the MS7 and MS10 microsatellite markers from patients with recurrent malaria are depicted in Fig. 5 and Table 3. All were treated with CQ

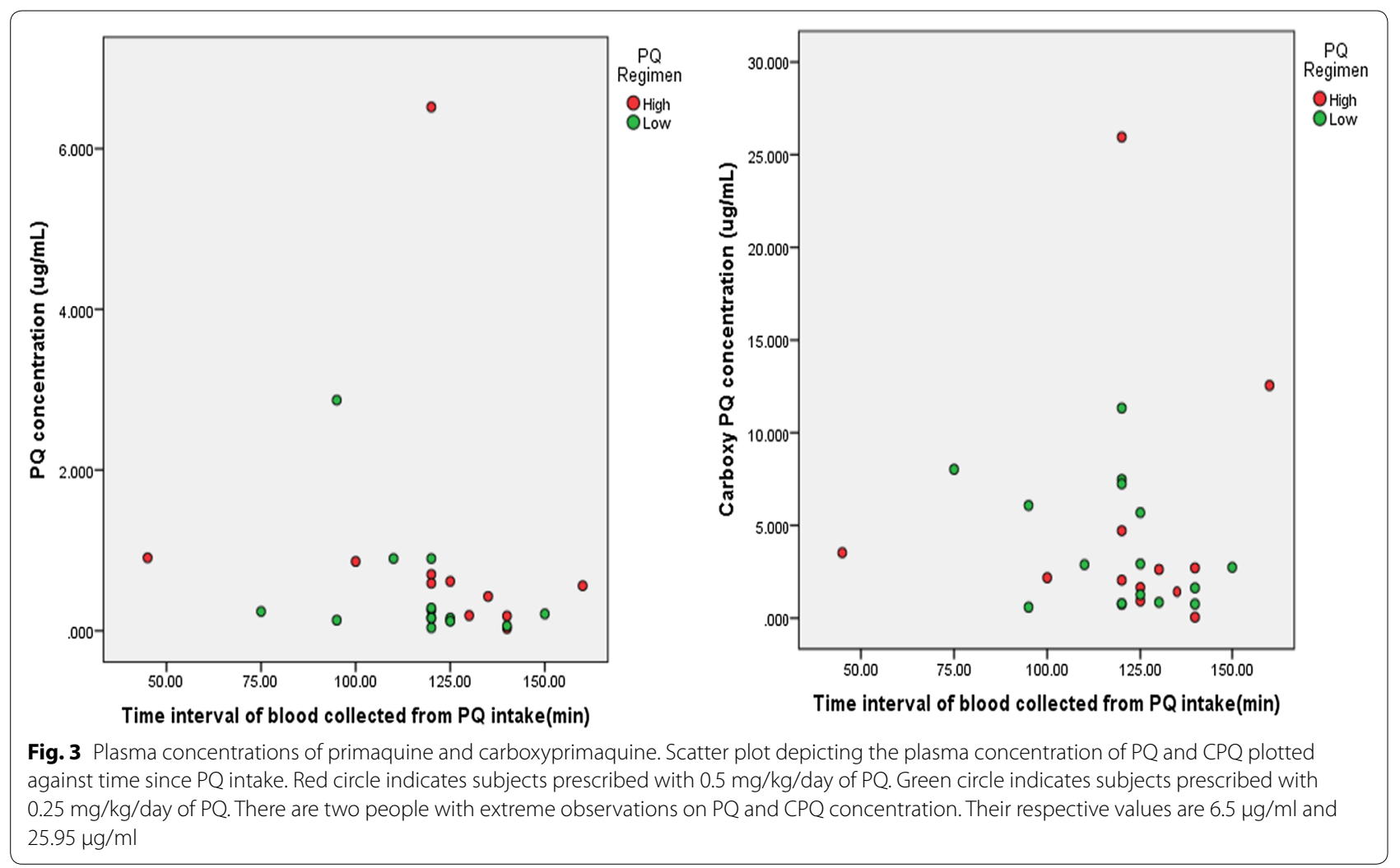


Table 3 Clinical characteristics, drug concentrations and genotyping of Plasmodium vivax among patients with recurrences

\begin{tabular}{|c|c|c|c|c|}
\hline & Patient 1 & Patient 2 & Patient 3 & Patient 4 \\
\hline Age (years) & 22 & 57 & 20 & 60 \\
\hline Gender & Male & Male & Male & Male \\
\hline Weight (kg) & 84.7 & 83 & 70 & 60 \\
\hline Body mass index & 28.40 & 29.76 & 25.40 & 23.73 \\
\hline Past h/o malaria & Yes & No & Yes & No \\
\hline Clinical phenotype of index episode & Non-severe & Non-severe & Non-severe & Non-severe \\
\hline Schizonticidal drug & Chloroquine & Artesunate + Doxycycline & Chloroquine & Chloroquine \\
\hline Regimen of PQ & High & Low & Low & High \\
\hline Actual dose of PQ received (mg/day) & 45.0 & 22.5 & 15.0 & 30.0 \\
\hline Actual dose of PQ received (mg/kg) & 0.53 & 0.27 & 0.21 & 0.50 \\
\hline Time to first recurrence (days) & 105 & 100 & 93 & 80 \\
\hline Clinical phenotype of recurrent episode & Non-severe & Non-severe & Non-severe & Non-severe \\
\hline Schizonticidal drug of recurrence & Chloroquine & Chloroquine & Chloroquine & Chloroquine \\
\hline PQ dose during recurrent episode (mg/day) & 45.0 & 15.0 & 37.5 & 30.0 \\
\hline \multicolumn{5}{|l|}{ Drug levels during index episode } \\
\hline PQ Level $(\mu \mathrm{g} / \mathrm{ml})$ & 6.518 & 0.240 & 0.159 & NA \\
\hline CPQ Level $(\mu \mathrm{g} / \mathrm{ml})$ & 4.714 & 8.026 & 0.746 & NA \\
\hline \multicolumn{5}{|l|}{ Drug levels during recurrence } \\
\hline PQ Level $(\mu \mathrm{g} / \mathrm{ml})$ & 0.267 & NA & 0.399 & NA \\
\hline CPQ Level $(\mu \mathrm{g} / \mathrm{ml})$ & 3.873 & NA & 0.536 & NA \\
\hline \multicolumn{5}{|l|}{ Amplicon sizes (MS7) } \\
\hline Initial infection & 342 & 351 & 351 & 345 \\
\hline Recurrent infection & 342 & 351 & 351 & 345 \\
\hline \multicolumn{5}{|l|}{ Amplicon sizes (MS10) } \\
\hline Initial infection & 263 & 254 & 290 & 290 \\
\hline Recurrent infection & 263 & 254 & 290 & 290 \\
\hline
\end{tabular}

NA not available

followed by PQ of $0.5 \mathrm{mg} / \mathrm{kg}$ for 14 day. Characteristics of patients with relapses are in Table 3.

\section{Discussion}

This pilot study assessed the tolerability, safety and effectiveness of two radical cure PQ dosage regimens $(0.25 \mathrm{mg} / \mathrm{kg} / \mathrm{day}, 0.5 \mathrm{mg} / \mathrm{kg} /$ day up to 14 days $)$. Both proved very effective. PQ is readily absorbed from the gastrointestinal tract, undergoes high first pass metabolism and is extensively distributed into body tissues. The plasma concentration peaks within 1-3 h after ingestion. PQ has a plasma elimination half-life of $4-9 \mathrm{~h}$ in healthy adults [15]. The metabolism of PQ is complex. A large number of metabolites have been identified. There are two main pathways, one via CYP450 2D6 and other CYP enzymes to reactive intermediates which are thought to mediate antimalarial activity and also haemolytic toxicity, and the other (via monoamine oxidase) to the biologically inert CPQ. CPQ is much more slowly eliminated than the parent compound with an elimination half-life of 22-30 h in healthy adults and so it is a potentially useful measure of adherence [16].

The present cohort consisted predominantly males; the gender imbalance is typical of patient population in the study setting and that of many others in malaria endemic areas of Asia [10, 17-19]. Although radical curative efficacy of observed PQ is usually over $90 \%$, it is widely 


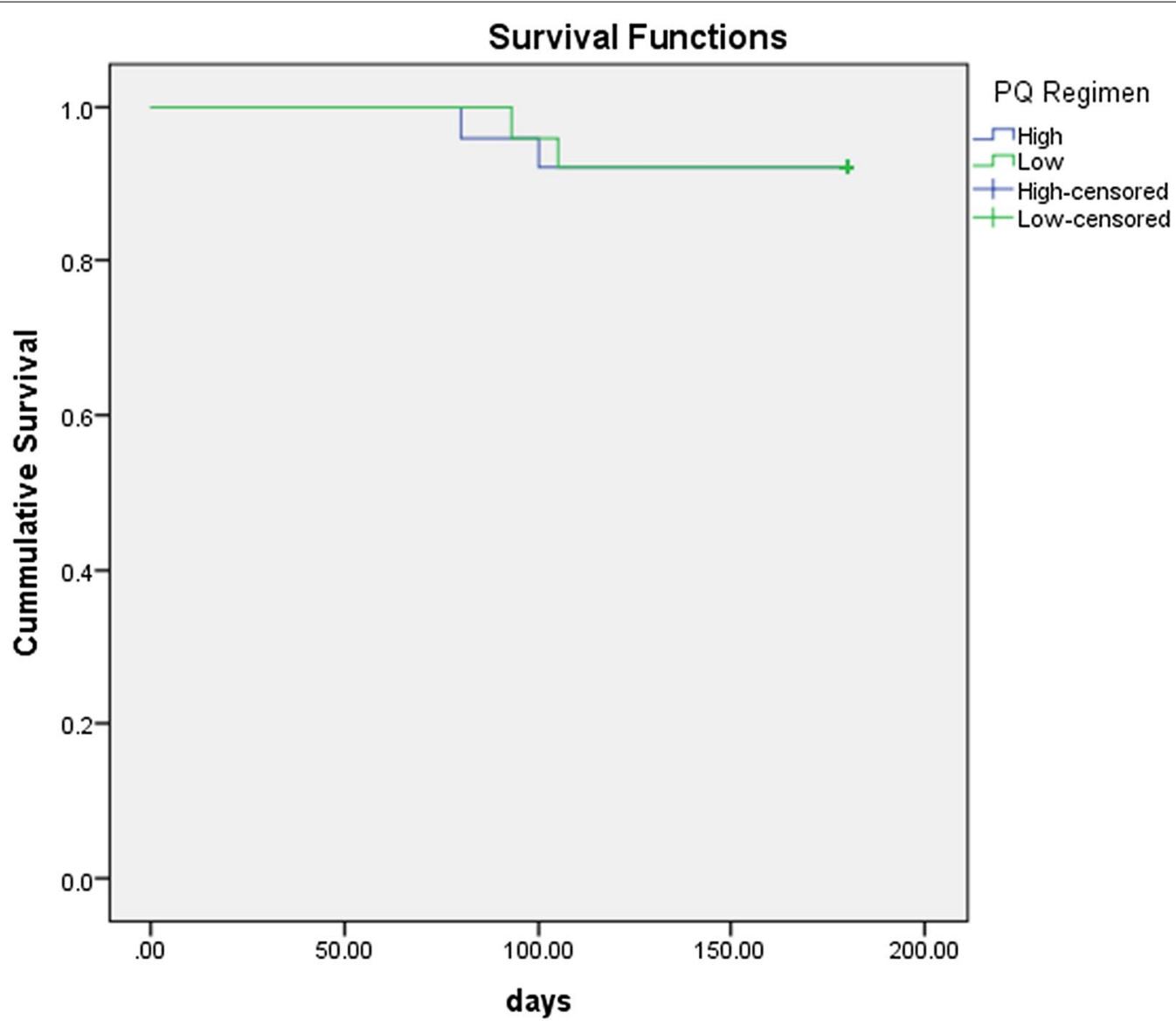

Fig. 4 Kaplan Meir survival curve of time to recurrence across two groups

thought that adherence is poor to the 14 day regimens currently recommended. This small pilot study indicates that with appropriate explanation to the patients the effectiveness is good-in this series $\sim 89 \%$. It is highly likely that the four recurrences resulted from relapses as each pair of acute and recurrent isolates had the same microsatellite genotype but each differed from the other $[20,21]$. Of the three relapses which had drug level measurement, one had very low day 7 CPQ concentrations strongly suggesting that the subsequent relapse resulted from poor adherence. One patient with relapse had high concentration of PQ during the index episode as well as during the recurrence, which may be suggestive of poor metabolizer phenotype. The prevalence of CYP2D6 poor metabolizers in this area is not known, but even if this is low, this small study suggests good PQ susceptibility. There was no difference between the high and low dose regimens of $\mathrm{PQ}$ in therapeutic effectiveness supporting previous studies from the Indian sub-continent and South America [7, 22-24]. A total dose of $3.5 \mathrm{mg}$ base/ $\mathrm{kg}$ seems sufficient for maximum hypnozoitocidal effects outside East Asia and Oceania. Plasmodium vivax cases recorded at health facilities during the non-transmission season likely arise from reactivation of dormant liverstages. In the transmission season $P$. vivax cases are presumed to be arising both from new mosquito infections and relaps. [25]. The interval to relapse ranged between 80 and 105 days in this study which is longer than usual 


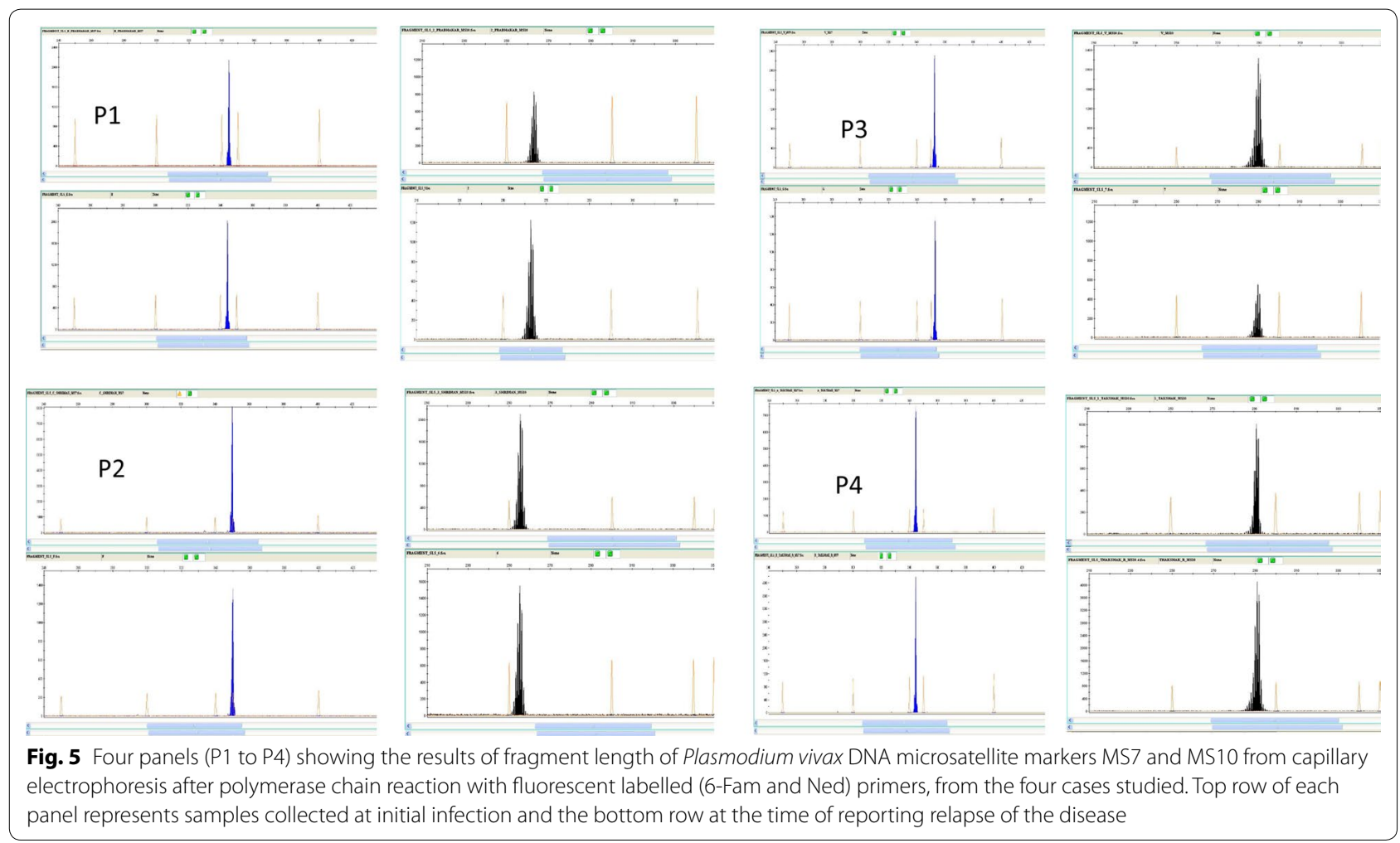

in East Asia, but is consistent with some studies from India which suggest an intermediate duration of latency [26-28].

This was a small study, and one-third of recruited patients did not complete the full 6 months follow up. This comparison was, therefore, underpowered to show significant differences between the two treatment arms. Nevertheless the effectiveness results do support the current dosing recommendation of PQ $3.5 \mathrm{mg}$ base $/ \mathrm{kg}$ total dose radical cure regimen in South India.

\section{Conclusion}

The recurrence rate of vivax malaria in this study was $8 \%$ at 6 months follow-up and it occurred equally in high dose as well as low dose PQ regimens. Recurrence cases were of non-severe phenotype and genotyping suggested all four recurrences were homologous (isogenic) relapses. This small pilot trial supports the effectiveness of the currently recommended lower dose $(0.25 \mathrm{mg} / \mathrm{kg} /$ day $) 14$ day $\mathrm{PQ}$ regimen for the radical cure of vivax malaria in South India.

\section{Abbreviations}

PQ: primaquine; $C P Q$ : carboxyprimaquine; $P C R$ : polymerase chain reaction; WHO: World Health Organization; CQ: chloroquine; ACT: artemisinin-based combination therapy; HPLC: high-performance liquid chromatography; QS: quinine sulfate; ISTD: internal standard; RP-HPLC: reversed phase-high-performance liquid chromatography; IQR: interquartile range; MS: microsatellite; USFDA: United States Food and Drug Administration.

\section{Authors' contributions}

Conception of the study: KS (K Saravu), CT. Participants'recruitment, follow-up, microscopy: SK, WX, SU. Contributed reagents/materials/analysis tools: KS (K Saravu), KS, KB. Data collection: SK, WX. Validation and HPLC analysis of samples: GB, NKS, KB, JPC. Performed genotyping experiments and analysis: $K S, A B$, AVS. Analysis and interpretation of data: KS (K Saravu), CT, VG, SK. Participated in design KS (K saravu), VG. Drafted manuscript: KS (K Saravu), CT, SK, NKS. Critically reviewed the draft: KS (K Saravu), KS, CT, KB, JPC, KS, SU. Read and approved the final manuscript, and agreed to be accountable for all aspects of the work: KS (K Saravu), CT, SK, WX, SU, GB, NKS, JPC, AB, AVS, VG, KS, KB. All authors read and approved the final manuscript.

\section{Author details}

1 Department of Medicine, Kasturba Medical College, Manipal Academy of Higher Education, Manipal, Madhava Nagar, Manipal, Karnataka 576104, India. ${ }^{2}$ Manipal McGill Centre for Infectious Diseases, Prasanna School of Public Health, Manipal Academy of Higher Education, Madhava Nagar, Manipal, Karnataka 576104, India. ${ }^{3}$ Department of Virus Research, Manipal Academy of Higher Education, Madhava Nagar, Manipal, Karnataka 576104, India. ${ }^{4}$ Department of Pharmaceutical Quality Assurance, Manipal College of Pharmaceutical Sciences, Manipal Academy of Higher Education, Madhava 
Nagar, Manipal, Karnataka 576104, India. ${ }^{5}$ Department of Cell \& Molecular Biology, School of Life Sciences, Manipal Academy of Higher Education, Madhava Nagar, Manipal, Karnataka 576104, India. ${ }^{6}$ Department of Statistics, Manipal Academy of Higher Education, Madhava Nagar, Manipal, Karnataka 576104, India. ${ }^{7}$ Department of Medicine, Dr. TMA Pai Hospital, Udupi, Melaka Manipal Medical College, Manipal Academy of Higher Education, Madhava Nagar, Manipal, Karnataka 576104, India.

\section{Acknowledgements}

The authors would like to acknowledge Dr. Manjunath Hande, Dr. B. A. Shastry, Dr. Mukhyaprana Prabhu, Dr. Shubha Sheshadri, Dr. Rama Bhat, Dr. Raviraj Acharya, Dr. Shivashankar and Dr. Sudha Vidyasagar (Clinicians, Department of Medicine, Kasturba Medical College, Manipal) who helped in participant recruitment. Authors are immensely grateful to all the participants' of this study. This study was supported by a seed grant award from Manipal McGill Center for Infectious Diseases, MAHE, Manipal.

\section{Competing interests}

The authors declare that they have no competing interests.

\section{Availability of data and materials}

The datasets used and analysed during the current study are available from the corresponding author on reasonable request.

\section{Consent for publication}

Not applicable.

\section{Ethics approval and consent to participate}

Study was commenced after obtaining ethical clearance (MUEC/021/2016-17) from Manipal Academy of Higher Education, Ethics Committee. Individuals were enrolled in the study after informed consent was obtained and all unique identifiers information were removed from study data and were stored in a secure location.

\section{Funding}

This study was supported by a seed Grant Award from Manipal McGill Center for Infectious Diseases, MAHE, Manipal (Grant No. MAC ID/SGA/2016/04).

\section{Publisher's Note}

Springer Nature remains neutral with regard to jurisdictional claims in published maps and institutional affiliations.

Received: 7 July 2018 Accepted: 30 August 2018

Published online: 03 September 2018

\section{References}

1. Mendis K, Sina BJ, Marchesini P, Carter R. The neglected burden of Plasmodium vivax malaria. Am J Trop Med Hyg. 2001;64:97-106.

2. WHO. World Malaria Report 2008. Geneva: World Health Organization; 2008. WHO/HTM/GMP/2008.1.

3. Anvikar AR, Shah N, Dhariwal AC, Sonal GS, Pradhan MM, Ghosh SK, et al. Epidemiology of Plasmodium vivax malaria in India. Am J Trop Med Hyg. 2016;95(Suppl 6):108-20.

4. The malERA Refresh Consultative Panel on Tools for Malaria Elimination. malERA: An updated research agenda for diagnostics, drugs, vaccines, and vector control in malaria elimination and eradication. PLoS Med. 2017;14:e1002455.

5. Recht J, Ashley EA, White NJ. Use of primaquine and glucose-6-phosphate dehydrogenase deficiency testing: divergent policies and practices in malaria endemic countries. PLoS Negl Trop Dis. 2018;12:e0006230.

6. Rishikesh K, Saravu K. Primaquine treatment and relapse in Plasmodium vivax malaria. Pathog Glob Health. 2016;110:1-8.

7. Durand S, Cabezas C, Lescano AG, Galvez M, Gutierrez S, Arrospide $\mathrm{N}$, et al. Efficacy of three different regimens of primaquine for the prevention of relapses of Plasmodium vivax malaria in the Amazon Basin of Peru. Am J Trop Med Hyg. 2014;91:18-26.

8. Directorate of National Vector Borne Disease Control Programme, MOHFW I. National Drug Policy on Malaria 2013. http://nvbdcp.gov.in/ Doc/National-Drug-Policy-2013.pdf. Accessed 25 Aug 2018.

9. CDC. Guidelines for treatment of malaria in the United States. Treatment table update, May. 2013. http://www.uphs.upenn.edu/bugdrug/antib iotic_manual/cdcmalariarx2013.pdf. Accessed 25 Aug 2018.

10. Saravu K, Kumar R, Ashok H, Kundapura P, Kamath V, Kamath A, et al. Therapeutic assessment of chloroquine-primaquine combined regimen in adult cohort of Plasmodium vivax malaria from primary care centres in southwestern India. PLoS One. 2016;11:e0157666.

11. Kumar R, Guddattu V, Saravu K. Therapeutic assessment of primaquine for radical cure of Plasmodium vivax malaria at primary and tertiary care centres in Southwestern India. Korean J Parasitol. 2016;54:733-42.

12. WHO. Guidelines for the treatment of malaria. Geneva: World Health Organization; 2015. http://apps.who.int/iris/bitstream/handle/10665 1162441/9789241549127_eng.pdf?sequence=1. Accessed 25 Aug 2018.

13. Karunaweera ND, Ferreira MU, Hartl DL, Wirth DF. Fourteen polymorphic microsatellite DNA markers for the human malaria parasite Plasmodium vivax. Mol Ecol Notes. 2007;7:172-5.

14. Parkhurst GW, Nora MV, Thomas RW, Carson PE. High-performance liquid chromatographic-ultraviolet determination of primaquine and its metabolites in human plasma and urine. J Pharm Sci. 1984;73:1329-31.

15. Mihaly GW, Ward SA, Edwards G, Orme ML, Breckenridge AM. Pharmacokinetics of primaquine in man: identification of the carboxylic acid derivative as a major plasma metabolite. Br J Clin Pharmacol. 1984;17:441-6.

16. National Center for Biotechnology Information. PubChem Compound Database; $\mathrm{CID}=4908$, Primaquine, https://pubchem.ncbi.nlm.nih.gov/ compound/4908. Accessed 25 Aug 2018.

17. Saravu K, Rishikesh K, Kamath A, Shastry AB. Severity in Plasmodium vivax malaria claiming global vigilance and exploration-a tertiary care centrebased cohort study. Malar J. 2014;13:304.

18. Saravu K, Kumar R, Ashok H, Kundapura P, Kamath V, Kamath A, et al. Therapeutic assessment of chloroquine-primaquine combined regimen in adult cohort of Plasmodium vivax malaria from primary care centres in southwestern India. PLoS One. 2016;11:1-6.

19. Kumar R, Saravu K. Severe vivax malaria: a prospective exploration at a tertiary healthcare centre in southwestern India. Pathog Glob Health. 2017;111:148-60.

20. Bright AT, Manary MJ, Tewhey R, Arango EM, Wang T, Schork NJ, et al. A high resolution case study of a patient with recurrent Plasmodium vivax infections shows that relapses were caused by meiotic siblings. PLoS Negl Trop Dis. 2014;8:e2882.

21. Koepfli C, Mueller I. Malaria epidemiology at the clone level. Trends Parasitol. 2017;33:974-85.

22. Valdes A, Epelboin L, Mosnier E, Walter G, Vesin G, Abboud P, et al. Primaquine $30 \mathrm{mg} /$ day versus $15 \mathrm{mg} /$ day during 14 days for the prevention of Plasmodium vivax relapses in adults in French Guiana: a historical comparison. Malar J. 2018;17:237.

23. AdakT, Sharma VP, Orlov VS. Studies on the Plasmodium vivax relapse pattern in Delhi, India. Am J Trop Med Hyg. 1998:59:175-9.

24. Srivastava HC, Sharma SK, Bhatt RM, Sharma VP. Studies on Plasmodium vivax relapse pattern in Kheda district, Gujarat. Indian J Malariol. 1996;33:173-9.

25. Golassa L, White MT. Population-level estimates of the proportion of Plasmodium vivax blood-stage infections attributable to relapses among febrile patients attending Adama Malaria Diagnostic Centre, East Shoa Zone, Oromia, Ethiopia. Malar J. 2017;16:301.

26. Chu CS, Phyo AP, Lwin KM, Win HH, San T, Aung AA, et al. Comparison of the cumulative efficacy and safety of chloroquine, artesunate, and chloroquine-primaquine in Plasmodium vivax malaria. Clin Infect Dis. 2018. https://doi.org/10.1093/cid/ciy319.

27. Kim JR, Nandy A, Maji AK, Addy M, Dondorp AM, Day NPJ, et al. Genotyping of Plasmodium vivax reveals both short and long latency relapse patterns in Kolkata. PLoS One. 2012;7:e39645.

28. White NJ. Determinants of relapse periodicity in Plasmodium vivax malaria. Malar J. 2011;10:297. 